Research Article

\title{
China's Economic Growth, Energy Efficiency, and Industrial Development: Nonlinear Effects on Carbon Dioxide Emissions
}

\author{
Donghai Zhou, Binxia Chen, Jiahui Li, and Yuanying Jiang (iD \\ College of Science, Guilin University of Technology, Guilin 541004, China \\ Correspondence should be addressed to Yuanying Jiang; jyy@glut.edu.cn
}

Received 3 February 2021; Revised 10 April 2021; Accepted 21 May 2021; Published 1 June 2021

Academic Editor: Xiaohua Ding

Copyright (c) 2021 Donghai Zhou et al. This is an open access article distributed under the Creative Commons Attribution License, which permits unrestricted use, distribution, and reproduction in any medium, provided the original work is properly cited.

\begin{abstract}
This paper analyzes the time-varying impacts of China's economic growth, energy efficiency, and industrial development on carbon dioxide $\left(\mathrm{CO}_{2}\right)$ emissions from 1970 to 2019 . First, we examined and found that there are two significant structural changes in the $\mathrm{CO}_{2}$ sequence over the years, and there was a significant nonlinear relationship among the four. The first nonlinear structural model constructed is the TVP regression model. According to the Bayesian model comparison criterion, TVP-SV-VAR was selected as the second constructed model from four types of VAR models containing nonlinear structures. The results show that the conduction intensity value of energy use efficiency to $\mathrm{CO}_{2}$ emissions has increased year by year, from 0.45 in 1971 to 0.97 in 2019. The short-term transmission mechanism of energy use efficiency to carbon emissions is the most significant. The conduction intensity of China's economic growth on $\mathrm{CO}_{2}$ emissions increases year by year. China's economic growth plays a major role in long-term $\mathrm{CO}_{2}$ emission reduction. The impact of industrial development on $\mathrm{CO}_{2}$ emissions reached a peak of 0.34 in 1977 , and the intensity of the impact has basically stabilized at 0.26 .
\end{abstract}

\section{Introduction}

Global warming caused by the growth of carbon emissions has become a major challenge to human beings. At present, the emission of carbon dioxide and other greenhouse gases is in urgent need of control, which has been the consensus of the international community. Since the United Nations Framework Convention on Climate Change (UNFCCC) in 1992, the international community has started to cooperate on carbon emission control (The United Nations Framework Convention on Climate Change (UNFCCC) was adopted by the United Nations General Assembly on May 9, 1992, and entered into force on March 21, 1994). The legally binding Kyoto Protocol and the Paris Agreement entered into force in 2005 and 2016, respectively (the Kyoto Protocol was formulated by the United Nations Framework Convention on Climate Change (UNFCCC) at the third meeting in December 1997 and came into force on February 16, 2005; the Paris Agreement was adopted at the Paris Climate Change Conference on December 12, 2015). In the context of international efforts to control carbon emissions, China should also respond positively and assume important social responsibilities. However, as China is still a developing country, its economic development has a rigid demand for energy consumption, which leads to high carbon emissions.

Figure 1 compares the $\mathrm{CO}_{2}$ emissions of several typical countries, namely, China, the United States, India, Japan, Germany, Brazil, and Canada. It can be seen from the figure that in 1970 China's $\mathrm{CO}_{2}$ emissions are roughly in line with those of Japan and Germany, a fifth of those of the United States, and after a period of sharp increases they average $10.35 \%$ between 2003 and 2011. China's $\mathrm{CO}_{2}$ emissions surpassed those of the United States in 2005 and by 2019 were 2.26 times those of the United States, 10 times those of Japan, and 16 times those of Germany. In the past 50 years from 1970 to 2019, the average growth rate of China's $\mathrm{CO}_{2}$ emissions is $5.43 \%$, higher than those of India and Brazil, both being developing countries, which are $5.11 \%$ and $3.17 \%$, respectively. This is far beyond the emission levels of developed countries like the United States, Japan, and Germany, which are $0.22 \%, 0.67 \%$, and $-0.83 \%$, respectively. The task of carbon emission reduction in the future is very 


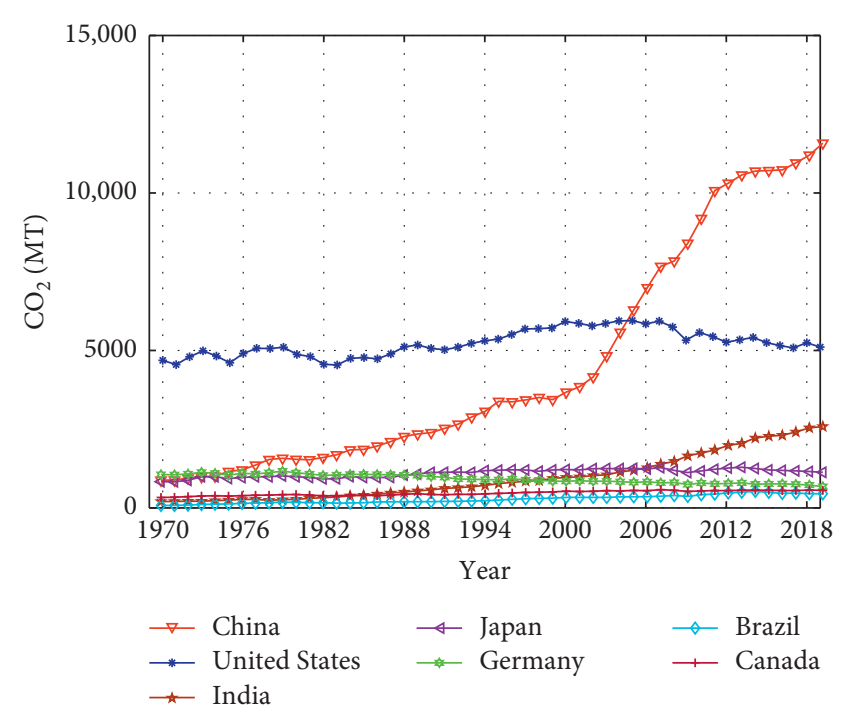

Figure 1: Comparison of annual $\mathrm{CO}_{2}$ emissions by country (the $\mathrm{CO}_{2}$ emission data of 6 countries comes from the Emissions Database for Global Atmospheric Research (EDGAR): https:// edgar.jrc.ec.europa.eu/).

difficult. As a result, China is committed to reducing $\mathrm{CO}_{2}$ emissions initiatives that have become the focus of global attention. Researching the recent studies on $\mathrm{CO}_{2}$ emissions by scholars around the world, it is found that the analysis of $\mathrm{CO}_{2}$ emissions and related factors in China is always in a high proportion. Besides, from the perspective of China's development situation, China's current carbon emission reduction is still in the deepening process, but its target policy of carbon neutrality makes the path of emission reduction steeper and more difficult to achieve. Based on the above analysis, it is of great practical significance to study the influencing factors of China's $\mathrm{CO}_{2}$ emission for controlling global carbon emission.

On September 22, 2020, China stressed that it will enhance its national intended contribution and adopt more effective policies and measures, aiming to peak its emissions by 2030 and striving to become carbon-neutral by 2060 (China announced this goal at the general debate of the 75th session of the UN General Assembly on September 22, 2020). This is the first time China has specified a carbon neutrality date for the world and is the largest climate commitment yet made by any country to reduce global warming expectations. In this context, we believe that it is necessary to grasp the emission reduction potential of various factors that affect carbon emissions, so as to focus on promoting carbon dioxide emission reduction. The rapid economic growth is accompanied by serious energy depletion and environmental pollution, among which the greenhouse gas effect caused by $\mathrm{CO}_{2}$ emissions is particularly prominent. Is there any dynamic change in the intensity of $\mathrm{CO}_{2}$ emissions from economic growth over the years? This is the question we want to study. In recent years, China has paid more and more attention to the improvement of production efficiency, industrial development, and clean energy utilization. Can the energy efficiency improved by transforming the economic growth mode or improving the technological level be able to significantly curb $\mathrm{CO}_{2}$ emissions? How important is the improvement of energy efficiency in affecting changes in carbon emissions? This is a question of great interest to us. In recent years, China's industrial sector has developed rapidly and, at the same time, industrial development has a rigid demand for energy consumption. Whether industrial development is the most important factor that promotes changes in carbon emissions is also a question of great interest to us. In the discussion of these issues, this article believes that the core logic is to straighten out the dynamic relationship and long-term and short-term effects between China's $\mathrm{CO}_{2}$ emissions and various influencing factors. We will grasp the emission reduction potential of each influencing factor and formulate and adjust various policies according to the motivation. Finally, we will implement precise policies to achieve the goal of carbon reduction and, at the same time, provide a more reasonable basis for a series of measures such as promoting carbon neutrality.

The research ideas of this article are as follows: (1) Since the founding of the People's Republic of China, China's economic growth, energy efficiency, and industrial development have experienced several large increases and fluctuations, $\mathrm{CO}_{2}$ emissions have also been greatly affected, and structural changes may have occurred. Therefore, we used the Bai-Perron breakpoint test method to test whether and when there are structural changes in carbon emissions during the sample period. (2) We performed BDS and RESET nonlinear tests on the data structure and found that there is a significant nonlinear relationship between China's carbon emissions and economic growth, energy efficiency, and industrial development. This means that the use of a model with a nonlinear structure is basis for modeling China's carbon emissions and economic growth, energy efficiency, and industrial development. (3) We constructed the first nonlinear model. The first nonlinear structural model constructed was the time-varying parameter regression (TVP-R) model. The time-varying nature of variable coefficients can more accurately capture the data characteristics of time series. (4) We constructed the second nonlinear model. According to the Bayesian model comparison criterion, we finally selected TVP-SV-VAR from the four types of VAR models containing nonlinear structures as the second nonlinear structure model and then used the three-dimensional time-varying parameter impulse response function to analyze in detail the conduction process of China's economic growth, energy efficiency, and industrial development on carbon emissions, including conduction direction, conduction intensity, etc. We conducted a global measurement of the time-varying dynamic effects of the three factors.

The innovations of this article are as follows:

(1) At present, research on carbon emissions and its main influencing factors methodologically agrees that the quantitative relationship between carbon emissions and various influencing factors is established. Obviously, this setting has a great limitation: 
the lack of model structure comparison. Therefore, in order to avoid the unfoundedness of the model setting, this paper first conducts a nonlinear test based on the BDS and RESET methods. From the results, we know that there is a significant nonlinear relationship between carbon emissions and China's economic growth, energy efficiency, and industrial development. Furthermore, according to the Bayesian model comparison criterion, four types of vector autoregressive (VAR) models containing linear and nonlinear structures are compared. This approach improves the lack of basis in the selection of the measurement model in the relevant empirical literature and, at the same time, verifies the results of the nonlinear test. In addition, we construct a timevarying parameter (TVP) regression model, and the dynamic trend of time-varying coefficients shows that China's economic growth, energy efficiency, and industrial development have obvious time-varying characteristics. This shows that the time-varying parameter model is better than the traditional constant coefficient model.

(2) In the model study, time-varying parameters (TVP) and stochastic fluctuation (SV) factors are included in the study of carbon emission factors. Since Black [1] proposed SV, it has been widely used in the financial field. In recent years, SV has been increasingly included in the empirical analysis of macroeconomics by scholars [2-4]. However, there is no relevant carbon emission research to introduce the TVP-SV model.

(3) In the calculation process of the logarithmic marginal likelihood, an additional importance sampling step is required to integrate the parameters required by the model. This paper adopts an adaptive importance sampling method to solve this problem. When fitting the state space model and the random walk process of time-varying parameters, the Bayesian calculation can be performed more efficiently based on the fast band sparse matrix algorithm instead of the traditional Kalman filter.

The remainder of the paper is structured as follows: Section 2 is the literature review. Section 3 describes the methodology and data. Section 4 presents the empirical results and analysis. Finally, Section 5 summarizes conclusions and policy recommendations.

\section{Related Studies}

In terms of the influencing factors of carbon emissions, academia has not yet formed a unified and clear definition. Generally speaking, the influencing factors of carbon emission refer to the production activities and living behaviors that directly or indirectly cause carbon emission. Since the 1970s, the research on the influencing factors of carbon emission has been paid more and more attention. In recent years, scholars from various countries have conducted a large number of studies on the influencing factors of carbon emissions from the aspects of industrial structure, GDP, population size, opening to the outside world, fixed asset investment, energy efficiency, and energy structure. In terms of analysis methods, there are mainly factor decomposition method, Granger causality test method, correlation coefficient method, multiple regression model or VAR model, etc. This paper gives a brief review of the current research status.

2.1. Impact of Economic Growth on $\mathrm{CO}_{2}$ Emissions. The rapid economic growth will lead to serious energy depletion and environmental pollution problems, among which the greenhouse gas effect caused by $\mathrm{CO}_{2}$ emission is particularly prominent, and economic growth is the main factor inducing carbon emissions. Domestic and foreign scholars mainly focus on two aspects in their research on the relationship between economic development and carbon emissions: first, whether there is an Environmental Kuznets Curve (EKC) relationship between economic development and carbon emissions; second, the impact of economic development on total carbon emissions. The research on EKC first appeared in Grossman and Krueger [5] which took the impact of the North American Free-Trade Agreement (NAFTA) on the environment as the research object and found the inverted $U$-shaped curve relationship between per capita income and environmental pollution. After that, Panayotou [6] proposed the concept of EKC. There is no consistent conclusion on the existence of EKC. Holtz-Eakin and Selden [7], Galeotti et al. [8], and Zheng et al. [9] believe that there is an inverted $U$-shaped relationship between per capita income and carbon emissions. Chinese scholars have also conducted many studies on the EKC. Wang and Wang [10] believed that there is a certain correlation between China's carbon emissions and economic development, but there is still a long economic development process away from the threshold point of the Kuznets Curve. Du et al. [11] showed that there was an $N$-type relationship between carbon emissions and China's per capita GDP. When studying the impact of economic development on carbon emissions, economic development and other influencing factors are generally analyzed within a framework. In the research on the influencing factors of carbon emission, the main mainstream is the regression analysis based on the IPAT model and the factor decomposition analysis based on Kaya identity, both of which take economic development as one of the influencing factors for analysis. Guan et al. [12] combined input-output analysis with the IPAT model to study the impact of five driving factors on China's carbon emissions from 1980 to 2002 and found that per capita GDP had the most significant promoting effect. Feng and Zou [13] analyzed $\mathrm{CO}_{2}$ emissions factors, based on the improved Kaya identities, the data of 1971-2005 with no residual decomposition. The result shows that in the factor of promoting the growth of carbon emissions, the rapid development of the increase of population and economy occupied the main position, and in curbing carbon emissions, energy efficiency has played a larger role. Yang et al. [14] theoretically analyze the direct impact of environmental 
regulation on carbon emissions and its indirect effects on carbon emissions through foreign direct investment (FDI), energy consumption, industrial structure, and technological innovation. Li et al. [15] focus on the relationships between $\mathrm{CO}_{2}$ emissions for energy consumption and influential factors: per capita GDP, urbanization level, energy intensity, and total energy consumption. Guo [16] decomposed China's carbon emissions from 1995 to 2007 from the two aspects of industry and region, and the research confirmed that the most important factor leading to the increase of carbon emissions was the expansion of economic aggregate. Begum et al. [17] used the Dynamic Ordinary Least Squared (DOLS) method to measure the relationship and dynamic impact of economic growth and forest area on carbon dioxide emissions in Malaysia, and the research showed that economic growth and deforestation had a negative impact on carbon emissions. Other examples of the specific analysis of economic activities include Xu et al. [18], Zou [19], and Sheng et al. [20].

2.2. Impact of Energy Utilization on $\mathrm{CO}_{2}$ Emissions. In recent years, as global energy consumption continues to increase, $\mathrm{CO}_{2}$ emissions have risen sharply. It is of great practical significance for energy conservation and emission reduction to study the internal mechanism of carbon emission explosion from the perspective of energy utilization. Therefore, energy intensity is widely used by many scholars to explore $\mathrm{CO}_{2}$ factors influencing emissions changes. Dong et al. [21], Krozer [22], Li [23], and other relevant documents agree that the decline of energy intensity has a good restraining effect on carbon emissions, and the decline of energy intensity is usually accompanied by the change of economic growth mode or the improvement of technological level. Yabe [24] studied the change of Japan's carbon emissions from 1985 to 1995 and analyzed its influencing factors by using the inputoutput method. The results showed that the development of production technology and environmental protection technology during the bubble economy improved energy use efficiency and thus reduced carbon emissions. Song and $\mathrm{Lu}$ [25] demonstrated that the important reason for the fluctuation of carbon emissions from 1990 to 2005 was the difference in economic growth mode by factor decomposition of $\mathrm{CO}_{2}$ emissions generated by energy consumption, and the economic growth mode of "high investment, low efficiency, and large emissions" was the direct cause of the dramatic increase of carbon emissions from 2000 to 2004. Zhang et al. [26] extended the research time to 2006 and concluded that the decline in energy intensity since 1991 was the most important factor restraining the increase of carbon emissions, and the popularization of fuel conversion and renewable energy also played a positive role in carbon emission reduction. Zhang [27] used the input-output method to measure the change of the mode of economic development and determine whether it can affect the carbon intensity; the result shows that, from 1987 to 2007 due to change in the way of economic development, China's carbon intensity declined up to $66.02 \%$ of GDP, and the key factor which affected the carbon intensity was a drop in the change of energy intensity.

\subsection{Impact of Industrial Development on $\mathrm{CO}_{2}$ Emissions.} The industrial sector has an important impact on carbon emissions due to its high energy consumption, so the research on the energy intensity of the industrial sector has attracted the attention of academic circles. However, according to Jiang and Lin [28], Zheng et al. [29], and others' research, simple to light industry and service industry transformation of the industrial structure adjustment cannot achieve the goal of carbon emissions reduction, so analysis of the industrial sector and its deep relationship with carbon emissions becomes particularly important. Greening et al. [30] study the industry sectors in Organisation for Economic Co-operation and Development (OECD) countries, and the results show that the change in the energy intensity of the production sector is the most important reason for the decline in carbon emissions in the sector. Ang et al. [31] conducted a decomposition study on eight industries involved in the industrial sector in China from 1985 to 1990 and concluded that the change in industrial output had a positive effect on carbon emissions, while the decline in energy intensity effectively inhibited the increase of carbon emissions. Liu et al. [32] expanded the research object to the Chinese industrial sector of 36 industries, analyzed the industrial sector's carbon emissions between 1998 and 2005, and thought that the overwhelming contributors to the change of China's industrial sectors' carbon emissions were the industrial activity and energy intensity; if the industry internal structure changes, this can reduce carbon emissions by $35.14 \%$.

The abovementioned scholars have studied carbon emissions and their main influencing factors. However, the current research mainly focuses on the study of its long-term influencing factors or assumes that its influencing coefficient is constant. Obviously, this setting has many limitations. Since the founding of the People's Republic of China in 1949, China's economic growth, energy efficiency, and industrial development have experienced several major growth rates and fluctuations, and its carbon emissions have also been greatly affected, possibly resulting in structural changes. Therefore, the dynamic evolutionary history between carbon emission and various influencing factors cannot be fully described under the framework of constant coefficient or constant quantity relationship. Based on this, we performed tests and found that there were two significant structural changes in $\mathrm{CO}_{2}$ sequences over the years, and there was a significant nonlinear relationship between them and economic growth, energy efficiency, and industrial development. Therefore, a dynamic model with a nonlinear structure is used to study the emission reduction potential of the three factors, and the Bayesian MCMC method is used to estimate the model parameters.

\section{Description of Methods and Data}

3.1. TVP Regression Model. The TVP regression model can be evolved through the multiple linear regression model. The traditional multiple linear regression model has the following form: 


$$
y_{t}=\beta_{1}+x_{2, t} \beta_{2}+x_{3, t} \beta_{3}+\cdots+x_{k, t} \beta_{k}+\varepsilon_{t}, t=1, \ldots, T,
$$

where $y$ is the dependent variable, $1, x_{2, t}, \ldots, x_{k, t}$ is $k$ regression variables, $\varepsilon_{1}, \ldots, \varepsilon_{T} \sim$ i.i.d. $N\left(0, \sigma^{2}\right)$, and $\beta_{1}, \ldots, \beta_{k}$ is the correlation regression coefficient. Let $y=\left(y_{1}, \ldots, y_{T}\right)^{\prime}, \beta=\left(\beta_{1}, \ldots, \beta_{k}\right)^{\prime}$, and (1) be rewritten as

$$
y=X \beta+\varepsilon, \varepsilon \sim N\left(0, \sigma^{2} I_{T}\right) .
$$

If the coefficient $\beta$ in the multiple linear regression model is assumed to be changing with time, the TVP regression model in the following form can be obtained:

$$
\begin{aligned}
y_{t} & =x_{t}^{\prime} \beta_{t}+\varepsilon_{t}, \varepsilon_{t} \sim N\left(0, \sigma_{t}^{2}\right), & & t=1,2, \ldots, T, \\
\beta_{t+1} & =\beta_{t}+\mu_{t}, \mu_{t} \sim N(0, \Sigma), & & t=0,1, \ldots, T-1,
\end{aligned}
$$

where $x_{t}$ is a vector of $k \times 1$, and $\beta_{t}$ is a vector of timevarying coefficients, assuming that $\beta_{0}=0, \mu_{0} \sim N\left(0, \Sigma_{0}\right), \gamma$ $>0, h_{0}=0$.

3.2. VAR and Its Extended Models. The VAR model proposed by Sims [33] can analyze the comprehensive and complex dynamic structural relationship between endogenous variables and promote the wide application of dynamic analysis of economic systems. It is one of the mainstream models in the world today. On the basis of Sims [33], Primiceri [2] constructed the TVP-SV-VAR model. This model can not only obtain the difference of variable relationship with time, but also describe the heteroscedasticity between data. The introduction of SV greatly improves the accuracy of model estimation and promotes the wide application of dynamic analysis of economic system.

Firstly, the traditional VAR model is defined as follows:

$$
B_{0} y_{t}=B_{1} y_{t-1}+\cdots+B_{s} y_{t-s}+\varepsilon_{t}, \quad \varepsilon_{t} \sim N(0, \Sigma) \text {. }
$$

$t=s+1, \ldots, n, y_{t}=\left(\mathrm{CO}_{2, t}, \mathrm{PCG}_{t}, \mathrm{EI}_{t}, \mathrm{IAV}_{t}\right) \prime, B_{0}$ is the coefficient matrix of the contemporaneous relationship between variables, $B_{1}, \ldots, B_{s}$ are the coefficient matrices of lagged variables, and $\varepsilon_{t}$ is the structural impact of the $k \times 1$ dimension. Referring to the form of Chan and Eisenstat [4], assuming that the equation coefficients are time-varying and the standard deviation of the random error term is SV, the TVP-SV-VAR model is obtained:

$$
B_{0 t} y_{t}=\mu_{t}+B_{1 t} y_{t-1}+\cdots+B_{p t} y_{t-p}+\varepsilon_{t}, \quad \varepsilon_{t} \sim N\left(0, \Sigma_{t}\right),
$$

where $\mu_{t}$ is the $n \times 1$ vector of the time-varying intercept, $n$ is the number of variables, $B_{1 t}, \ldots, B_{p t}$ are the VAR coefficient matrices of $n \times n, B_{0 t}$ is a lower triangular matrix of $n \times n$, $\Sigma_{t}=\operatorname{diag}\left(\exp \left(h_{1 t}\right), \ldots, \exp \left(h_{n t}\right)\right)$, and the logarithmic volatility $h_{t}=\left(h_{1 t}, \ldots, h_{n t}\right)^{\prime}$ obeys the following random walk:

$$
h_{t}=h_{t-1}+\varsigma_{t}, \quad \varsigma_{t} \sim N\left(0, \Sigma_{h}\right) .
$$

For the purpose of model comparison, we separate the TVP into two groups. The first group consists of the $k_{\beta} \times 1$ vector of time-varying intercepts and coefficients associated with the lagged observations: $\beta_{t}=\operatorname{vec}\left(\left(\mu_{t}, B_{1 t}, \ldots, B_{p t}\right)^{\prime}\right)$. The second group is the $k_{\gamma} \times 1$ vector of time-varying coefficients that characterize the contemporaneous relationships between the variables, which we denote as $\gamma_{\mathrm{t}}$; it consists of the free elements of $B_{0 t}$ stacked by rows. Note that $k_{\beta}=$ $n(n p+1)$ and $k_{\gamma}=n(n-1) / 2$. With these two groups of parameters defined, we can rewrite (5) as

$$
y_{t}=\widetilde{X}_{t} \beta_{t}+W_{t} \gamma_{t}+\varepsilon_{t}, \quad \varepsilon_{t} \sim N\left(0, \Sigma_{t}\right),
$$

where $\tilde{X}_{t}=I_{n} \otimes\left(1, y_{t-1}^{\prime}, \ldots, y_{t-p}^{\prime}\right)$ and $W_{t}$ is an $n \times k_{\gamma}$ matrix that contains appropriate elements of $-y_{t}$. Finally, the above model can be further written as a generic state space model:

$$
y_{t}=X_{t} \theta_{t}+\varepsilon_{t}, \quad \varepsilon_{t} \sim N\left(0, \Sigma_{t}\right)
$$

where $X_{t}=\left(\tilde{X}_{t}, W_{t}\right)$ and $\theta_{t}=\left(\beta_{t}^{\prime}, \gamma_{t}^{\prime}\right)^{\prime}$ is of dimension $k_{\theta}=k_{\beta}+k_{\gamma}$. The vector of TVP $\theta_{t}$ in turn follows the following random walk process:

$$
\theta_{t}=\theta_{t-1}+\eta_{t}, \quad \eta_{t} \sim N\left(0, \Sigma_{\theta}\right)
$$

We treat the initial conditions $\theta_{0}$ as parameters to be estimated. The priors of the initial conditions $\theta_{0}$ and $h_{0}$ are both Gaussian: $\theta_{0} \sim N\left(a_{\theta}, V_{\theta}\right)$ and $h_{0} \sim N\left(a_{h}, V_{h}\right)$. Moreover, we assume that the error covariance matrices for the state equations are diagonal; i.e., $\Sigma_{\theta}=\operatorname{diag}\left(\sigma_{\theta 1}^{2}, \ldots, \sigma_{\theta k_{\theta}}^{2}\right)$, $\Sigma_{h}=\operatorname{diag}\left(\sigma_{h 1}^{2}, \ldots, \sigma_{h n}^{2}\right)$. The diagonal elements of $\Sigma_{\theta}$ and $\Sigma_{h}$ are independently distributed as

$$
\begin{aligned}
\sigma_{\theta i}^{2} & \sim \operatorname{IG}\left(v_{\theta i}, S_{\theta i}\right), \\
\sigma_{h i}^{2} & \sim \operatorname{IG}\left(v_{h j}, S_{h j}\right), \quad i=1, \ldots, k_{\theta}, j=1, \ldots, k_{h},
\end{aligned}
$$

where $\quad a_{\theta}=0, V_{\theta}=10 \times I_{k_{\theta}}, a_{h}=0, \quad V_{h}=10 \times I_{n}$, $v_{\theta i}=v_{h j}=5$, and $\sigma_{h j}^{2}=0.1^{2}$. Equations (6), (8), and (9) adopt the algorithm of Chan and Jeliazkov [34] based on a fast banded sparse matrix, instead of the traditional Kalman filter, and make calculation according to the process of Del and Primiceri [35] to ensure a more efficient simulation process.

Hamilton [36] believes that economic variables show different characteristics and laws in different states. For comparison, we also consider the RS-VAR model similar to Sims and Zha [37]. When the system is affected by mechanism changes, the parameter $\theta$ of the VAR process will change over time. More specifically, let $S_{t} \in\{1, \ldots, r\}$ denote the regime indicator at time $t$, where $r$ is the number of regimes. Then, regime-switching VAR is given by

$$
B_{0 S_{t}} y_{t}=\mu_{S_{t}}+B_{1 S_{t}} y_{t-1}+\cdots+B_{p S_{t}} y_{t-p}+\varepsilon_{t}, \quad \varepsilon_{t} \sim N\left(0, \Sigma_{S_{t}}\right) \text {, }
$$

where $\left(B_{0 j}, B_{1 j}, \ldots, B_{p j}\right)$ and $\Sigma_{j}$ for $j=1, \ldots, r$ are regimespecific parameters. The regime indicator $S_{t}$ is assumed to follow a Markov process with transition probability $P\left(S_{t}=j \mid S_{t-1}=i\right)=p_{i j}$. This regime-switching VAR is denoted as RS-VAR.

Table 1 shows the notation of all the above VAR models and their extended forms. 
TABLE 1: Model notation and feature description.

\begin{tabular}{lc}
\hline TVP-SV & The time-varying parameter VAR with SV in \\
(6), (8), and (9) \\
TVP & The same as TVP-SV but $h_{\mathrm{t}}=h_{0}$ and $\gamma_{t}=\gamma_{0}$ \\
CVAR & The constant coefficients VAR with $\theta_{t}=\theta_{0}, h_{t}=h_{0}$ \\
RS-VAR & The regime-switching VAR in (11) \\
\hline
\end{tabular}

3.3. Data. This article analyzes the driving force and emission reduction potential of China's economic growth (PCG), energy efficiency (EI) and industrial development (IAV) on carbon emissions $\left(\mathrm{CO}_{2}\right)$, and the data range is selected from 1970 to $2019 . \mathrm{CO}_{2}$ aggregate data are derived from the EDGAR; compared to other institutions that calculate $\mathrm{CO}_{2}$, EDGAR covers a wide range of areas. We used GDP per capita as the substitution variables of China's economic growth, and the data are obtained from the National Bureau of Statistics. Energy intensity is one of the important indicators to measure energy efficiency, reflecting the degree of economic dependence on energy; the lower the strength, the higher the energy efficiency. Energy intensity calculation formula is total energy consumption/GDP, energy consumption per unit of GDP. China is now in the process of industrialization, tending to need more energy consumption per unit GDP production and, therefore, to improve energy efficiency to achieve the goal of sustainable development, energy consumption, and GDP data from the National Bureau of Statistics. Referring to Ni et al.'s [38] method of industrial development, the proportion of nonagricultural employment to total employment (referred to as nonagricultural employment ratio) reflects the level of industrial development. Employed population data come from the National Bureau of Statistics (https://data.stats.gov.cn/).

Table 2 is a descriptive statistical analysis table for carbon emissions $\left(\mathrm{CO}_{2}\right)$, China's economic growth (PCG), energy efficiency (EI), and industrial development (IAV).

Figure 2 shows $\mathrm{CO}_{2}$, PCG, EI, and IAV in the sample period of 1970 to 2019 time-series trend chart; $\mathrm{CO}_{2}$, PCG, and IAV showed significant upward trends, which were in line with the expectation of the economic situation. Since 1978, the energy intensity has shown a significant downward trend, but the decline has been relatively slow in the past two decades. The reason is that China still uses industry and heavy industry as the main economic structure, which requires a large amount of energy to produce. When the economic structure is gradually transformed to be dominated by the service industry, the problem of high energy consumption can be improved, and the energy intensity will be greatly reduced.

3.4. Structural Change Test of Data. Since the founding of the People's Republic of China in 1949, China's economic growth, energy efficiency, and industrial development have experienced several major growth rates and fluctuations, and its carbon emissions have also been greatly affected, possibly resulting in structural changes.
TABle 2: Description of the statistical analysis.

\begin{tabular}{lcccc}
\hline Variables & $\mathrm{CO}_{2}$ & PCG & EI & IAV \\
\hline Mean & 4525.492 & 14137.32 & 5.747626 & 0.460686 \\
Median & 3227.400 & 4586.000 & 2.331008 & 0.467500 \\
Maximum & 11535.20 & 70892.00 & 16.10892 & 0.749003 \\
Minimum & 906.5620 & 279.0000 & 0.490480 & 0.192292 \\
Std. dev. & 3558.701 & 19876.03 & 5.622804 & 0.164636 \\
Skewness & 0.824740 & 1.488197 & 0.679336 & 0.104157 \\
Kurtosis & 2.132642 & 3.980820 & 1.807427 & 1.981306 \\
Jarque-Bera & $7.235618^{* *}$ & $20.46028^{* * *}$ & $6.808789^{* *}$ & 2.252357 \\
(Probability) & $(0.026841)$ & $(0.000036)$ & $(0.033227)$ & $(0.324270)$ \\
\hline
\end{tabular}

Note. The unit of $\mathrm{CO}_{2}$ is MT, the unit of PCG is Yuan, the unit of EI is Ten Thousand Tons of Standard Coal/RMB 100 Million Yuan, and the unit of IAV is the ratio. The symbols ${ }^{*},{ }^{* *}$, and ${ }^{* * *}$ mean significant at the level of $10 \%, 5 \%$, and $1 \%$, respectively.

Therefore, we used the Bai-Perron break test to answer two questions: Question 1: Does carbon emission show structural changes in the sample period? Question 2: if there is a structural change, at what point in time will it appear? It can be seen from the test results of the Bai-Perron breakpoint in Table 3 that there are two structural changes in the carbon emission sequence in the sample period, the first one in 2002 and the second one in 2012. Therefore, China's carbon emissions over the years can be divided into three periods, namely, 1970 to 2001 (phase I), 2002 to 2011 (phase II), and 2012 to 2019 (phase III). Figure 3 shows the trend of China's carbon emissions over three periods. In the first stage (1970-2001), China's carbon emissions were in a period of slow growth; especially during the period from 1995 to 1999, the carbon emissions basically did not increase or even show negative growth phenomenon. In the second stage (from 2002 to 2011), China's carbon emissions grew rapidly, mainly because after China joined the World Trade Organization at the end of 2001, the rapid growth of China's export led to the rapid development of China's economy and, at the same time, the export of resource-based products increased greatly, leading to the leap-forward growth of energy consumption. In the third phase (2012-2019), China's carbon emissions once again entered a period of slow growth. As China's economic development has entered the new normal phase, from high-speed growth to more intensive and sustainable high-quality development, its carbon emission pattern has also changed. Since the economy entered the new normal phase, carbon emission has gradually stabilized. The main reasons are as follows: First, China has been increasing energy efficiency and reducing energy intensity in major sectors of its economy. Second, the government has made great efforts to develop renewable energy and encouraged all provinces and cities to participate in national low-carbon development projects, which has achieved remarkable results in emission reduction. Third, the Chinese government has actively promoted the establishment of a nationwide carbon trading market and further utilized market forces to control carbon emissions. 


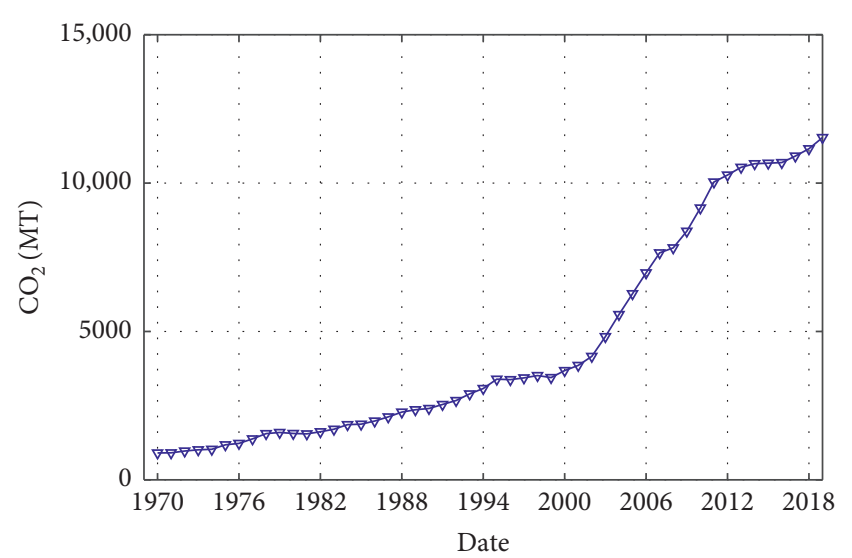

(a)

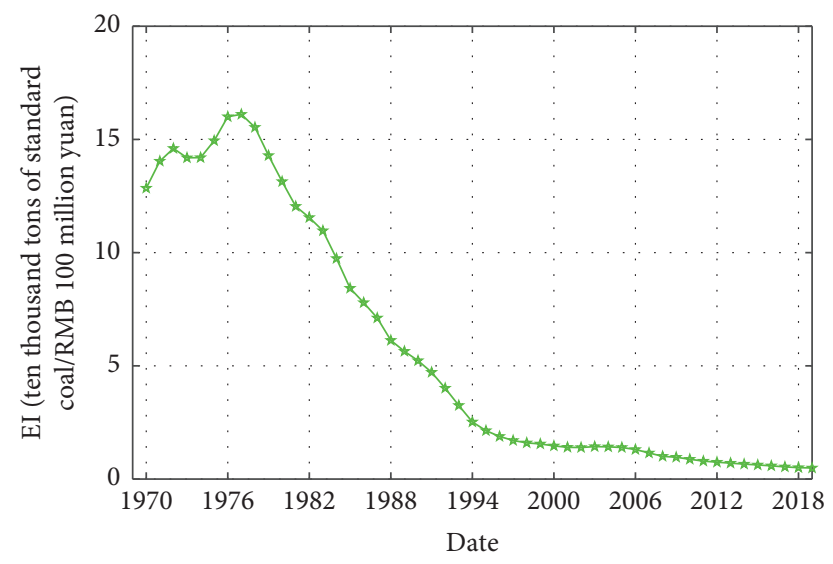

(c)

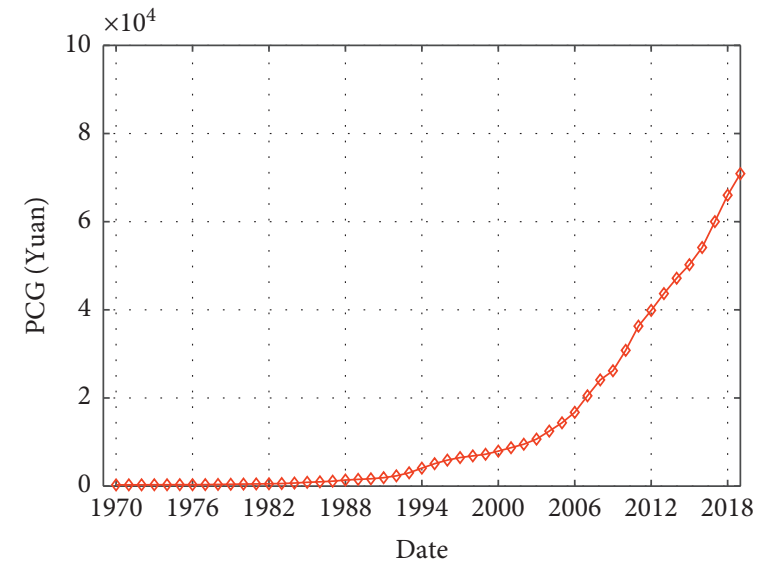

(b)

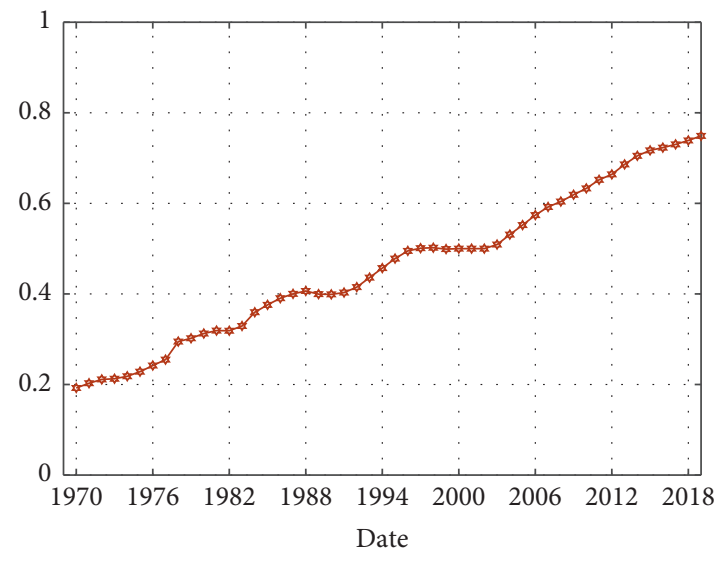

(d)

FIgUre 2: Chart of time series of original variables: (a) $\mathrm{CO}_{2}$; (b) PCG; (c) EI; (d) IAV.

TABle 3: Bai-Perron break test.

\begin{tabular}{lccc}
\hline Break test & F-statistic & Scaled $F$-statistic & Critical value \\
\hline 0 vs. 1 & $36.86146^{* * *}$ & 36.86146 & 8.02 \\
1 vs. 2 & $49.28111^{* * *}$ & 49.28111 & 9.56 \\
2 vs. 3 & 7.641745 & 7.641745 & 10.45 \\
\hline
\end{tabular}

Note. The first breakpoint: 2002; the second breakpoint: 2012.

\section{Empirical Results and Analysis}

4.1. Unit Root Test. In order to reduce the influence of data dimension and heteroscedasticity, the four data series of $\mathrm{CO}_{2}$, PCG, EI, and IAV were taken logarithm, respectively, to obtain the $\ln \mathrm{CO}_{2}, \ln \mathrm{PCG}, \ln \mathrm{EI}$, and $\operatorname{lnIAV}$ series. The $\ln \mathrm{CO}_{2}, \ln \mathrm{PCG}$, $\operatorname{lnEI}$, and $\ln I A V$ series were tested with the unit root test using the ADF test and PP test. The types of ADF test and PP test were determined according to $\ln \mathrm{CO}_{2}, \ln \mathrm{PCG}, \ln \mathrm{EI}$, and $\ln \mathrm{A} \mathrm{AV}$ sequence, difference sequence, and AIC criterion. The hysteresis order selection criterion for the ADF test was SIC, and Bartlett Kernel was the hysteresis order selection criterion for the PP test. It can be seen from Table 4 that the $p$ values of ADF and PP tests of the four variables are all greater than the significance level of 5\%, so the null hypothesis of the existence of unit root cannot be rejected for the four variables. After differential treatment of $\ln \mathrm{CO}_{2}, \ln \mathrm{PCG}, \operatorname{lnEI}$, and $\operatorname{lnIAV}$, the unit root test was performed again, and the results showed that the $p$ values of the ADF test and PP test were all less than the significance level of $5 \%$. The null hypothesis of the unit root was rejected, and the stability condition was considered to be satisfied. Table 5 is the descriptive statistical analysis table of the stationary series.

4.2. Nonlinear Characteristic Test of Carbon Emission Sequence. Taking $\Delta \mathrm{CO}_{2}$ as the dependent variable and $\triangle \mathrm{PCG}, \triangle \mathrm{EI}$, and $\triangle \mathrm{IAV}$ as independent variables, the regression model was constructed, and the model residual was used to conduct nonlinear test based on BDS and RESET methods. The regression model results are shown as follows (the VIF values of multicollinearity tests are all below 10), and the nonlinear test results based on BDS and RESET methods are shown in Table 6. As can be clearly seen from Table 6, the conclusions of the BDS test and RESET are very robust, and all the statistics reject the null hypothesis that there is only a linear trend in the carbon emission sequence at the significance level of $10 \%$. This means that there is a significant nonlinear relationship between carbon emissions and economic growth, energy efficiency, and industrial 


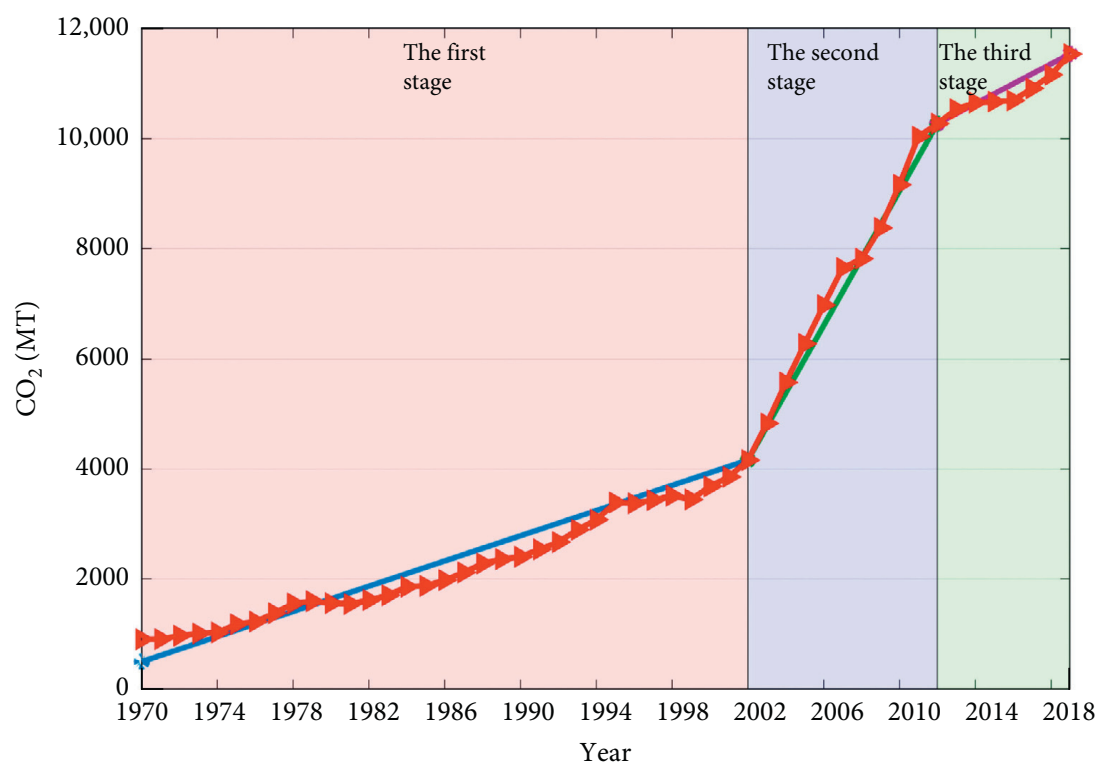

Figure 3: Three periods of China's carbon emissions over the years.

TABle 4: ADF unit root test.

\begin{tabular}{|c|c|c|c|c|c|}
\hline \multirow{2}{*}{ Variables } & \multicolumn{2}{|c|}{ ADF test } & \multicolumn{2}{|c|}{ PP test } & \multirow{2}{*}{ Test result } \\
\hline & ADF statistics & $p$ value & PP statistics & $p$ value & \\
\hline $\operatorname{lnCO} 2$ & -2.17972 & 0.4896 & -2.028535 & 0.5715 & Not smooth \\
\hline$\Delta \mathrm{CO}_{2}$ & $-4.45923^{* * *}$ & 0.0008 & $-4.49406^{* * *}$ & 0.0007 & Smooth \\
\hline $\ln P C G$ & -3.00289 & 0.1421 & -2.73828 & 0.2266 & Not smooth \\
\hline$\Delta \mathrm{PCG}$ & $-3.03398^{* *}$ & 0.0393 & $-2.98796^{* *}$ & 0.0432 & Smooth \\
\hline $\operatorname{lnEI}$ & -2.2858 & 0.4332 & -2.68155 & 0.2485 & Not smooth \\
\hline$\Delta \mathrm{EI}$ & $-3.00955^{* *}$ & 0.0411 & $-3.04345^{* *}$ & 0.0380 & Smooth \\
\hline $\operatorname{lnIAV}$ & -2.025325 & 0.2753 & -2.882964 & 0.0546 & Not smooth \\
\hline$\triangle \mathrm{IAV}$ & $-4.672079^{* * *}$ & 0.0024 & $-4.432691^{* * *}$ & 0.0009 & Smooth \\
\hline
\end{tabular}

Note. The symbols ${ }^{*},{ }^{* *}$, and ${ }^{* * *}$ mean significant at the level of $10 \%, 5 \%$, and $1 \%$, respectively.

TABle 5: Description and statistical analysis of stationary series.

\begin{tabular}{lcccc}
\hline Variables & $\Delta \mathrm{CO}_{2}$ & $\Delta$ PCG & $\Delta \mathrm{EI}$ & $\Delta \mathrm{IAV}$ \\
\hline Mean & 0.051908 & 0.113014 & -0.066645 & 0.027750 \\
Median & 0.046187 & 0.095168 & -0.065805 & 0.024534 \\
Maximum & 0.148364 & 0.298770 & 0.088707 & 0.145293 \\
Minimum & -0.021156 & -0.033694 & -0.253481 & -0.017242 \\
Std. dev. & 0.043457 & 0.064647 & 0.066469 & 0.026106 \\
Skewness & 0.444799 & 0.583209 & -0.151120 & 1.950398 \\
Kurtosis & 2.404997 & 3.557437 & 3.682588 & 1.901891 \\
Jarque-Bera & 2.338549 & 3.412175 & 1.137769 & 128.3234 \\
(Probability) & $(0.310592)$ & $(0.181575)$ & $(0.566157)$ & $(0.00000)$ \\
\hline
\end{tabular}

development. Therefore, if the traditional linear framework is used for analysis, significant deviations may occur in the test results, thus drawing biased conclusions on the factors affecting carbon emission.

$$
\begin{array}{r}
\Delta \mathrm{CO}_{2}=5.80 \times 10^{-5}+0.872593 \Delta \mathrm{PCG}+0.782531 \Delta \mathrm{EI}+0.194109 \Delta \mathrm{IAV} \\
(0.008921)\left(0.122240^{* * *}\right) \quad\left(0.116364^{* * *}\right) \quad(0.168071) \\
\text { adjusted } R-\text { squared }=0.613967 \\
F-\text { statistic }=23.85676^{* * *} .
\end{array}
$$


TABLE 6: Nonlinearity check based on BDS and RESET methods.

\begin{tabular}{lcccc}
\hline $\begin{array}{l}\text { Test } \\
\text { methods }\end{array}$ & df & $\begin{array}{c}\text { Embedding } \\
\text { dimension }\end{array}$ & Test statistics & $p$ values \\
\hline RESET & 4 & - & $2.211389^{*}$ & 0.0845 \\
\hline \multirow{2}{*}{ BDS } & - & 2 & $10.87009^{* * *}$ & 0.0000 \\
& - & 3 & $10.14338^{* * *}$ & 0.0000 \\
& - & 4 & $9.477264^{* * *}$ & 0.0000 \\
\hline
\end{tabular}

Note. Embedding dimension was selected as 2,3 , and 4 , and $\varepsilon$ as a fraction of range in $\mathrm{BDS}$ test. BDS test statistics are asymptotically normal distribution, and RESET statistics are $F$ distribution. ${ }^{*},{ }^{* *}$, and ${ }^{* * *}$ mean significant at the level of $10 \%, 5 \%$, and $1 \%$, respectively.

\subsection{TVP Model Construction and Parameter Estimation.} According to the nonlinear test results of BDS and RESET methods, there is a significant nonlinear relationship between China's carbon emissions and economic growth, energy efficiency, and industrial development. Therefore, in order to examine the potential of economic growth, energy efficiency, and industrial development on carbon emission reduction in China, this paper constructs a TVP regression model with nonlinear structure using $\Delta \mathrm{CO}_{2}, \Delta \mathrm{PCG}, \Delta \mathrm{EI}$, and $\triangle \mathrm{IAV}$ data series and obtains the parameter estimation results as shown in Table 7. According to the estimation results of Geweke convergence diagnosis, the original hypothesis that the estimated parameters have converged to the posterior distribution cannot be rejected. The noneffective impact factors are low for all parameters; even for $\sum_{33}$, the noneffective impact factor is about 30 , and MCMC samples 10000 times, from which at least $10000 / 30=333$ effective sample numbers (uncorrelated sample observations) can be obtained, which is sufficient to satisfy the posterior statistical inference. Next, the validity of the model parameter sampling estimates is further confirmed based on the sample autocorrelation functions, sample paths, and posterior densities of the parameters.. Thus, at least we get 10,000/ $45 \approx 222$ valid samples (not related to the sample observations), enough to meet the needs of the posterior statistical inference, posterior mean values are close to the real parameters, the model parameters of the simulation results are very effective, according to the parameters of the next sample autocorrelation function, and the density of sample path and posterior density further verify the effectiveness of the model parameter sampling estimation.

Figure 4 shows the sample autocorrelation function, MCMC simulation path, and posterior density of the selected parameters of the TVP regression model. If the sample autocorrelation coefficient rapidly deviates to zero as the number of sampling intervals increases, it indicates that the simulation path is stable. According to the first line of sample autocorrelation graph, after discarding the first 1000 "burn-in" periods, using the 10,000 samples, sample autocorrelation coefficient rapidly deviates towards zero, showing that the sampling method is very effective in producing low autocorrelation coefficient of the samples. According to the sample simulation path diagram, the sample simulation path of the selected parameter is judged to be relatively stable. Besides, it can be seen from the parameter posterior density diagram that the posterior density
TABLE 7: Parameter estimation and test of the TVP regression model.

\begin{tabular}{|c|c|c|c|c|c|}
\hline Parameter & Mean & $\begin{array}{l}\text { Std. } \\
\text { dev. }\end{array}$ & $\begin{array}{c}{[95 \% \mathrm{U}} \\
95 \% \mathrm{~L}]\end{array}$ & Geweke & Inefficiency \\
\hline$\sum_{11}$ & 0.0094 & 0.0076 & $\begin{array}{c}0.0024, \\
0.0303]\end{array}$ & 0.917 & 16.76 \\
\hline$\sum_{22}$ & 0.0146 & 0.0144 & $\begin{array}{c}{[0.0027} \\
0.0557]\end{array}$ & 0.995 & 19.60 \\
\hline$\sum_{33}$ & 0.0141 & 0.0150 & $\begin{array}{c}{[0.0027} \\
0.0554]\end{array}$ & 0.217 & 44.93 \\
\hline$\sigma$ & 0.0391 & 0.0043 & $\begin{array}{l}{[0.0316} \\
0.0485]\end{array}$ & 0.136 & 1.63 \\
\hline
\end{tabular}

function is in agreement with the posterior mean value of the parameters listed in Table 7. The above results show that the sampling and estimation of the model are stable and effective, which can be analyzed in the next step.

From Figure 5, TVP coefficient of the regression model of the time-varying dynamic graph, we can see that the impact of China's economic growth, energy efficiency, and industrial development on carbon emissions has obvious time-varying characteristics, building the time-varying parameter model is more competitive than the traditional constant coefficient model, and at the same time the change of the economy, energy, and environment policy and regulation and advances in technology cause the impact of various variables on carbon emissions to change. The following three factors are combined to analyze the conduction process of carbon emissions one by one:

(1) The fluctuating impact of China's economic growth on carbon emissions. From 1971 to 2019, the impact coefficient of China's economic growth on carbon emissions ranged from 0.65 to 0.96 , indicating that China's economic growth had a greater positive conduction intensity to carbon emissions and was an important driver of carbon emissions. At the same time, this result also shows that China's economic development has made great progress, but the economic growth mode with high energy consumption also brings a heavy burden to the air environment. Before 2010, the conduction intensity of China's economic growth to carbon emissions increased year by year. After that, though the conduction intensity showed a trend of weakening, it did not weaken greatly. Since 2011, the Chinese government has advocated the development concept of "green GDP" and committed per unit of GDP $\mathrm{CO}_{2}$ emissions should be $60-65 \%$ lower than 2005 in 2030 . To achieve this goal, we must accelerate the pace of transforming economic growth pattern and adjusting economic structure. Otherwise, the pattern of economic development with a high consumption of resources and high emission of pollution will lead to more serious carbon emission, which is not conducive to the realization of social sustainable development.

(2) The fluctuating influence of energy efficiency on carbon emission by coal. The influence coefficient of energy intensity on carbon emission is concentrated 

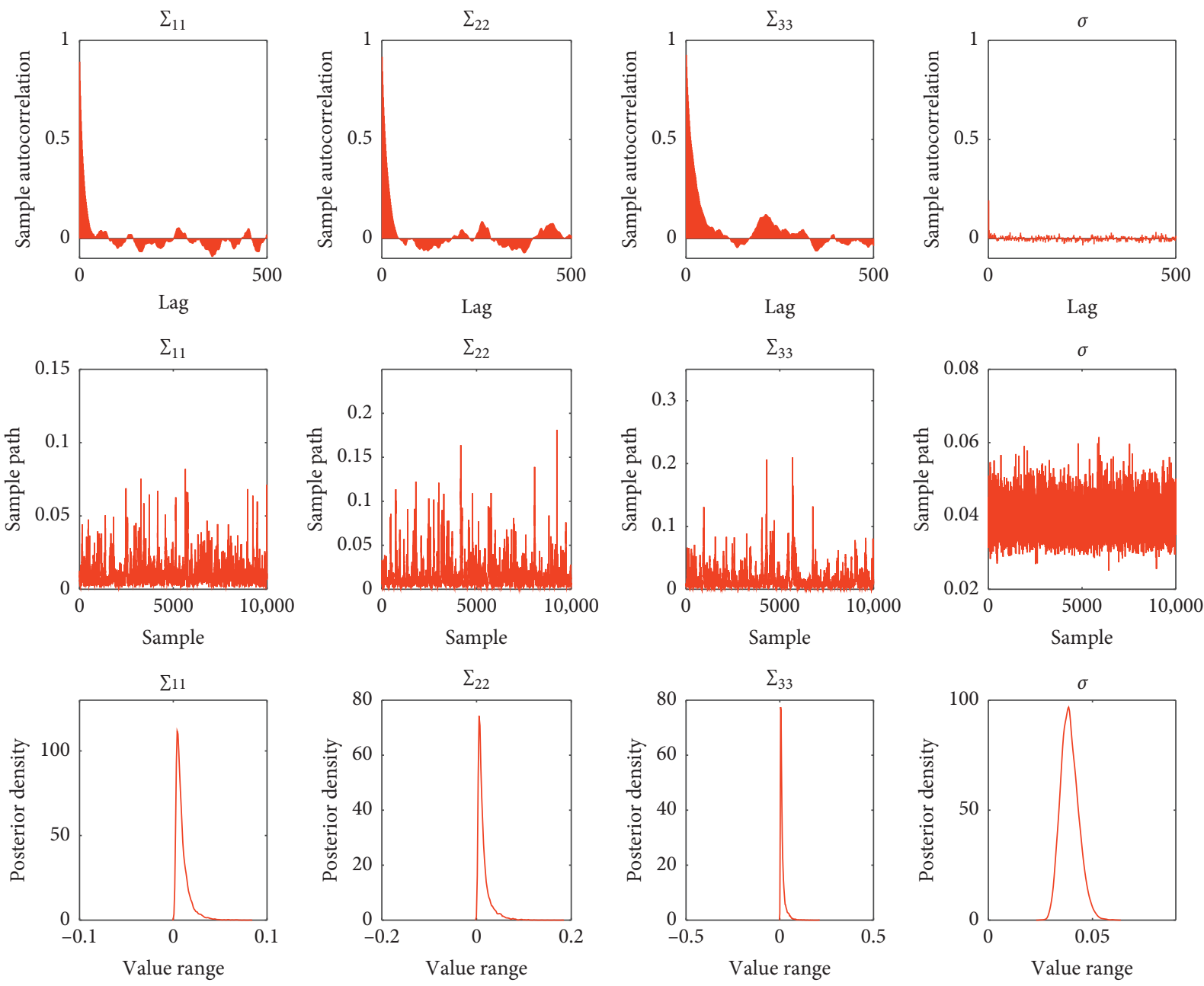

FIgURE 4: Sample autocorrelation function, sample path, and posterior density of TVP model parameters.
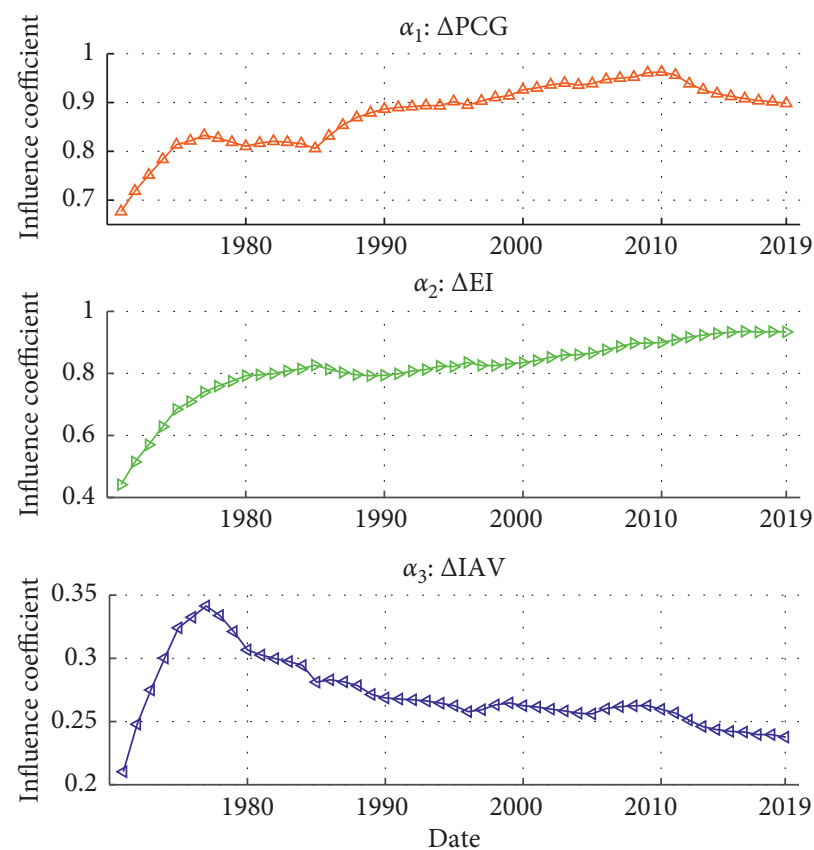

FIGURE 5: Time-varying coefficient trend diagram of TVP regression model. 
between 0.45 and 0.97 . Since 1971, the conduction intensity of energy intensity to $\mathrm{CO}_{2}$ has gradually increased and reached a peak of about 0.97 in 2019. Obviously, the elasticity of carbon emission to energy intensity is the largest, indicating that the transmission mechanism of energy intensity to carbon emission is the most significant and that the change of energy intensity plays a leading role in carbon emission reduction. Energy intensity reflects the degree of economic dependence on energy; the higher the intensity is, the greater the energy use per unit of GDP directly affects the increase of the carbon emissions in the atmosphere; therefore, to reduce energy intensity is the main way of reducing carbon emissions. This also confirms the IEA forecasts to 2050; reducing energy intensity can accomplish as much as $31 \%$ of emissions reduction targets.

(3) The fluctuating impact of industrial development on carbon emissions by coal. The influence coefficient of industrial development on carbon emissions was relatively weak. Before the reform and opening up in 1978, the influence of industrial development on carbon emissions showed a trend of increasing year by year and reached a peak of 0.34 in 1977 . After that, the influence intensity gradually weakened slightly and was stable at around 0.26 . Although the shortterm impact of industrial development on carbon emissions is weaker than that of economic growth and energy efficiency. In the long term, carbon emissions from industrial development have a significant environmental impact. As a result, China's industry needs to promote green transformation mode, reduce energy consumption and industrial coal consumption, and further reduce carbon emissions in the field of industry, to push China's implementation of the sustainable development in the future.

\subsection{Construction of TVP-SV-VAR Model}

4.4.1. Granger Causality Test. Table 8 shows the Granger causality test between China's economic growth, energy efficiency, industrial development, and carbon emissions. It is clear from the test results that China's economic growth, industrial development, and energy efficiency are all Granger causes of carbon emissions.

4.4.2. Model Comparison. In order to further explore the driving force and emission reduction potential of China's economic growth, energy efficiency, and industrial development for carbon emission, we established TVP-SV-VAR model. According to FPE, AIC, SC, and HQ information criteria, the optimal lag of TVP-SV-VAR model was selected as order 1. Next, the Bayesian model comparison method is adopted to compare the four types of vector autoregressive models with nonlinear structures. According to the structural change test results of the data, we add the RS-VAR
TABle 8: Granger causality test.

\begin{tabular}{lcc}
\hline Null hypothesis: & $F$-statistic & Prob. \\
\hline$\Delta$ PCG does not Granger-cause $\Delta \mathrm{CO}_{2}$ & 15.0860 & 0.0003 \\
$\Delta \mathrm{CO}_{2}$ does not Granger-cause $\Delta \mathrm{PCG}$ & 25.7510 & 0.0000 \\
$\Delta \mathrm{EI}$ does not Granger-cause $\Delta \mathrm{CO}_{2}$ & 4.07190 & 0.0495 \\
$\Delta \mathrm{CO}_{2}$ does not Granger-cause $\Delta \mathrm{EI}$ & 1.84189 & 0.1814 \\
$\Delta \mathrm{IAV}$ does not Granger-cause $\Delta \mathrm{CO}_{2}$ & 15.5192 & 0.0003 \\
$\Delta \mathrm{CO}_{2}$ does not Granger-cause $\Delta \mathrm{IAV}$ & 17.0632 & 0.0002 \\
\hline
\end{tabular}

TABLE 9: Logarithmic marginal likelihood results of four types of VAR models.

\begin{tabular}{lcccc}
\hline & TVP-SV-VAR & TVP-VAR & CVAR & RS-VAR $(r=3)$ \\
\hline Log-ML & $\mathbf{- 5 0 5 . 3}$ & -531.7 & -532.7 & -550.3 \\
Std. dev. & $\mathbf{( 0 . 2 7 )}$ & $(0.14)$ & $(0.03)$ & $(0.72)$ \\
\hline
\end{tabular}

TABle 10: Parameter estimation and test of TVP-SV-VAR model.

\begin{tabular}{|c|c|c|c|c|c|}
\hline Parameter & Mean & $\begin{array}{l}\text { Std. } \\
\text { dev. }\end{array}$ & $\begin{array}{c}{[95 \% \mathrm{U}} \\
95 \% \mathrm{~L}]\end{array}$ & Geweke & Inefficiency \\
\hline$\left(\Sigma_{\beta}\right)_{1}$ & 0.0963 & 0.0229 & $\begin{array}{c}{[0.0620} \\
0.1511]\end{array}$ & 0.675 & 10.92 \\
\hline$\left(\Sigma_{\beta}\right)_{2}$ & 0.0097 & 0.0024 & $\begin{array}{c}{[0.0063,} \\
0.0156]\end{array}$ & 0.484 & 11.03 \\
\hline$\left(\Sigma_{\beta}\right)_{3}$ & 0.0097 & 0.0025 & $\begin{array}{c}{[0.0063,} \\
0.0160]\end{array}$ & 0.766 & 19.02 \\
\hline$\left(\Sigma_{\beta}\right)_{4}$ & 0.0098 & 0.0025 & $\begin{array}{c}{[0.0063,} \\
0.0159]\end{array}$ & 0.327 & 8.79 \\
\hline$\left(\Sigma_{\beta}\right)_{5}$ & 0.0097 & 0.0026 & $\begin{array}{c}{[0.0062,} \\
0.0161]\end{array}$ & 0.289 & 13.82 \\
\hline$\left(\Sigma_{\beta}\right)_{6}$ & 0.0947 & 0.0216 & $\begin{array}{c}{[0.0627} \\
0.1463]\end{array}$ & 0.755 & 7.22 \\
\hline$\left(\Sigma_{a}\right)_{1}$ & 0.0096 & 0.0024 & $\begin{array}{c}{[0.0062} \\
0.0151]\end{array}$ & 0.527 & 13.02 \\
\hline$\left(\Sigma_{a}\right)_{2}$ & 0.0097 & 0.0025 & $\begin{array}{c}{[0.0063,} \\
0.0159]\end{array}$ & 0.430 & 10.27 \\
\hline$\left(\Sigma_{a}\right)_{3}$ & 0.0095 & 0.0023 & $\begin{array}{c}{[0.0062} \\
0.0153]\end{array}$ & 0.833 & 7.81 \\
\hline$\left(\Sigma_{h}\right)_{1}$ & 0.0978 & 0.0256 & $\begin{array}{c}{[0.0623} \\
0.1633]\end{array}$ & 0.170 & 10.82 \\
\hline$\left(\Sigma_{h}\right)_{2}$ & 0.0098 & 0.0025 & $\begin{array}{c}{[0.0064} \\
0.0159]\end{array}$ & 0.931 & 15.80 \\
\hline$\left(\Sigma_{h}\right)_{3}$ & 0.0096 & 0.0023 & $\begin{array}{c}{[0.0063} \\
0.0153]\end{array}$ & 0.881 & 14.82 \\
\hline
\end{tabular}

model with the number of zone states of 3 . Each logarithmic marginal likelihood is based on 10,000 synthetic likelihood estimates, of which the importance sampling density is constructed using 10,000 samples after the first 1000 "burnin" periods are discarded. According to the output results in Table 9, the logarithmic marginal likelihood value of TVPSV-VAR is -505.3 , and the logarithmic marginal likelihood values of TVP-VAR and CVAR are -531.7 and -532.7 , respectively. The logarithmic marginal likelihood of TVPSV-VAR model is significantly higher than that of TVPVAR model, indicating that TVP-SV-VAR model fully describes the degree of SV of data, and the model fitting effect is better. In addition, compared with TVP-SV-VAR, the log-marginal likelihood of the RS-VAR model with the 

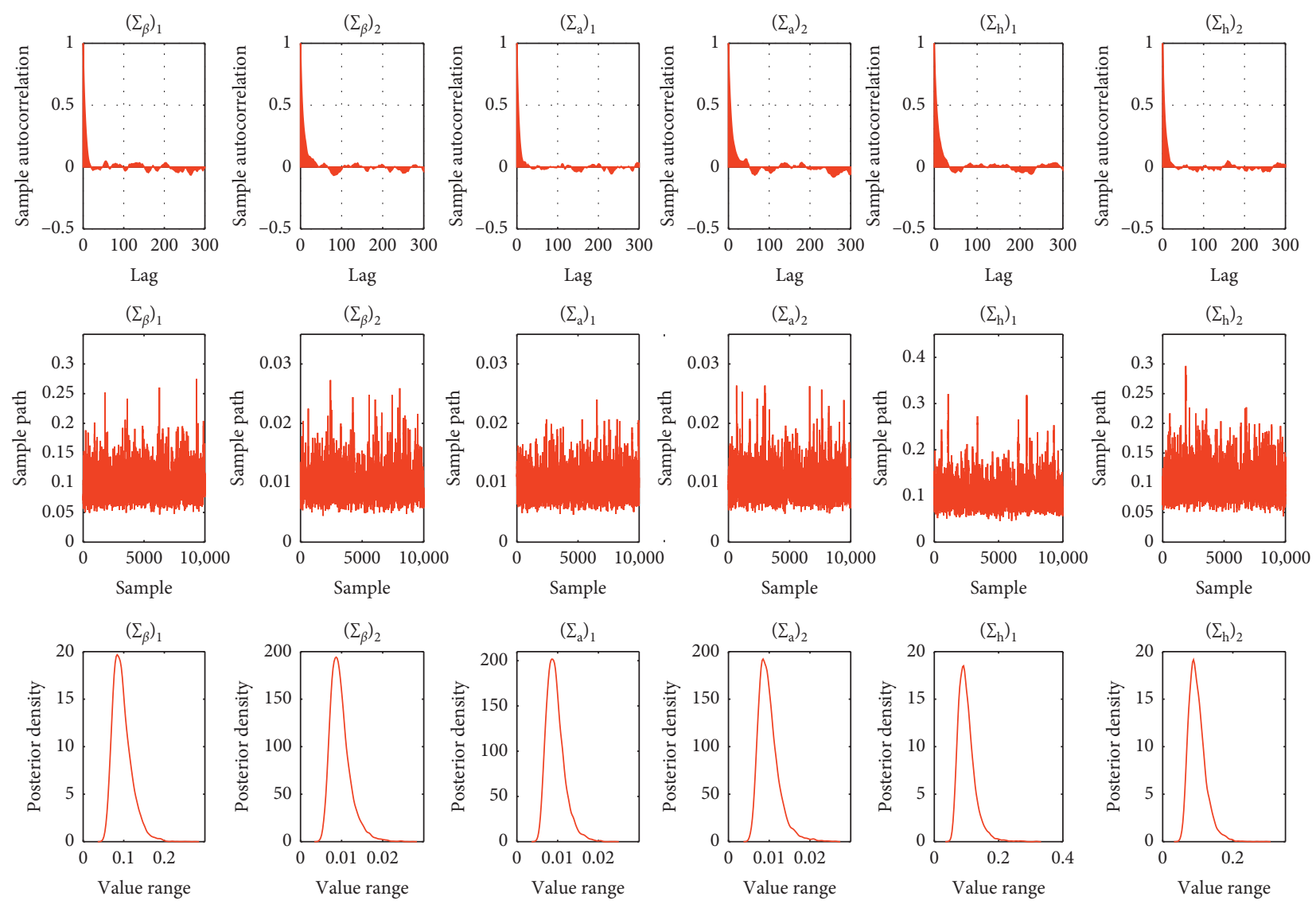

Figure 6: Sample autocorrelation function, sample path, and posterior density of TVP-SV-VAR parameters.

number of zone states of 3 still has a large gap, which indicates that the time-varying advantage of parameters is more prominent. Based on the above analysis, the TVP-SVVAR model with the largest logarithmic marginal likelihood is selected for empirical analysis below. It is obvious from the above comparative analysis that the model comparison avoids the baseless model setting to some extent.

4.4.3. Parameter Estimation of the TVP-SV-VAR Model. TVP-SV-VAR model parameter estimation and test results are shown in Table 10. According to the estimation results of Geweke's convergence diagnosis, the null hypothesis that the estimated parameters have converged to the posterior distribution cannot be rejected. Parameters of effective impact factor are generally low, enough to meet the needs of a posteriori statistical inference, posterior mean values are close to the real parameters, the model parameters of the simulation results are very effective, according to the parameters of the next sample autocorrelation function, and the density of sample path and posterior density further verify the effectiveness of the model parameter sampling estimation.

Figure 6 shows the sample autocorrelation function, MCMC simulation path, and posterior density of the selected parameters of the TVP-SV-VAR model. If the sample autocorrelation coefficient rapidly deviates to zero as the number of sampling intervals increases, it indicates that the simulation path has reached a plateau. According to the first line of sample autocorrelation graph, after discarding the first 1000 "burn-in" periods, using the 10,000 samples, sample autocorrelation coefficient rapidly deviates towards zero, showing that the sampling method is very effective in producing low autocorrelation coefficient of the samples. According to the sample simulation path diagram, the sample simulation path of the selected parameters is judged to be relatively stable. Furthermore, it can be seen from the parameter posterior density diagram that the posterior density function agrees with the posterior mean value of the parameters listed in Table 10. The above results show that the sampling and estimation of the model are stable and effective, which can be analyzed in the next step.

\subsubsection{Stereo Time-Varying Impulse Response Function.}

To comprehensively measure the time-varying dynamic effects of China's economic growth, energy efficiency, and industrial development on carbon emissions, Figure 7 shows that $\mathrm{CO}_{2}$ emissions, China's economic growth, energy efficiency, and industrial development are affected by a single unit of positive external impact on carbon emissions. The vertical axis is the response trend from 0 to 7 periods in advance, and the horizontal axis is all time points in the sample period. From the stereoscopic time-varying impulse response trend of the three shocks, it is obvious that carbon 


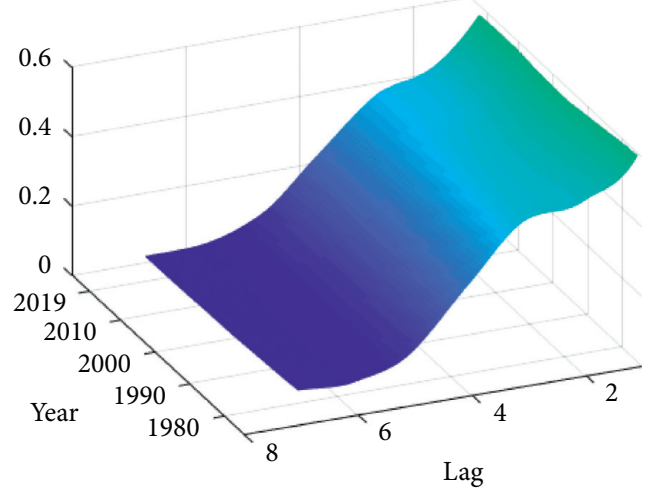

(a)

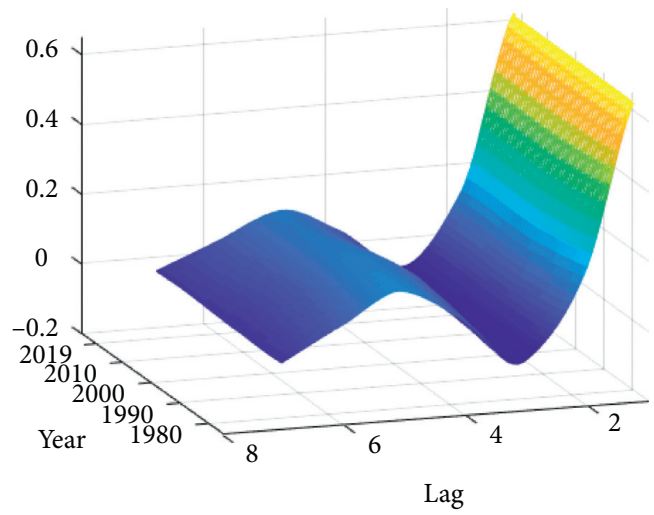

(c)

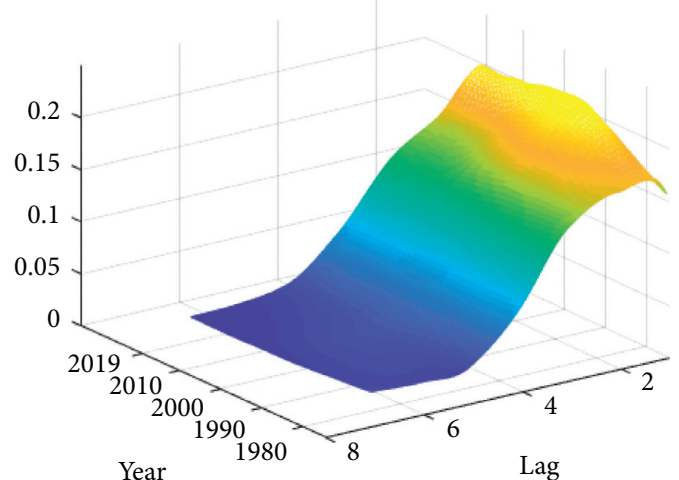

(b)

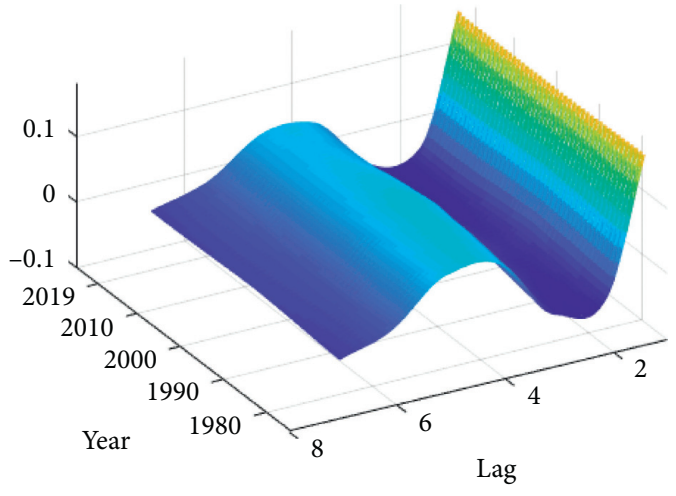

(d)

Figure 7: Analysis of stereo impulse response: (a) $\Delta \mathrm{CO}_{2} \uparrow \longrightarrow \mathrm{CO}_{2}$; (b) $\Delta \mathrm{PCG} \uparrow \longrightarrow \mathrm{CO}_{2}$; (c) $\Delta \mathrm{EI} \uparrow \longrightarrow \mathrm{CO}_{2}$; (d) $\Delta \mathrm{IAV} \uparrow \longrightarrow \mathrm{CO}_{2}$.

emission shows dynamic flexibility to China's economic growth, energy efficiency, and industrial development as a whole.

When $\mathrm{CO}_{2}$ emission is positively impacted by an external unit, it has a significant positive impact on itself and reaches the maximum impact intensity in the first phase, with an intensity value of 0.6 . With time, the positive impact of carbon emission growth gradually weakened and finally approached zero around the 6th phase. This indicates that the impact information on carbon emission growth will lead to an increase in carbon emission in the future, with a significant long-term impact effect. When a unit of positive impact is given to China's economic growth, both the current and future response values of carbon emissions are positive. After the maximum intensity value reaches 0.2 in the first phase, the response value declines at a faster rate. From the impact effect of all time points, the impact intensity of China's economic growth on carbon emissions has increased significantly since 2000 , which may be mainly due to the rapid growth of China's export after China joined the World Trade Organization at the end of 2001, which led to the rapid development of China's economy and led to the leap-forward growth of energy consumption. However, in order to ensure sustainable economic and social development, the government pays more and more attention to environmental governance and implements corresponding environmental protection policies to reduce carbon emissions. Therefore, in the long run, the impact of China's current economic growth on future carbon emissions is relatively weak. When a unit of positive impact is given to energy intensity, the carbon emission response value in the first phase is as high as 0.68 , which means that energy intensity has a stronger impact on carbon emission in the initial stage than the carbon emission itself. However, the impact of energy intensity shock on carbon emissions decreases rapidly after the second phase, which indicates that the short-term transmission mechanism of energy intensity on carbon emissions is the most significant and also that the change of energy intensity plays a short-term leading role in carbon emission reduction effect. High energy consumption means high pollution, and reducing energy intensity is the most important way to reduce carbon emissions. This conclusion is consistent with the TVP regression conclusion. Therefore, on the premise of not destroying the ecological environment, China should exploit and utilize more clean energy to promote the green and coordinated development of the economy. When a unit of positive impact is given to China's industrial development, the carbon emission response value is positive in the whole response period, and the maximum response value is 0.2 , indicating that the overall response intensity of industrial development and economic growth to carbon emission is very similar, but the impact of industrial development on carbon emission has a relatively short duration. 
TABLE 11: Variance decomposition of $\Delta \mathrm{CO}_{2}$.

\begin{tabular}{lccccc}
\hline Period & $\mathrm{SE}$ & $\Delta \mathrm{CO}_{2}$ & $\Delta \mathrm{PCG}$ & $\Delta \mathrm{EI}$ & $\Delta \mathrm{IAV}$ \\
\hline 1 & 0.04 & 28.16 & 27.97 & 41.12 & 2.76 \\
2 & 0.04 & 23.95 & 24.12 & 47.65 & 4.28 \\
3 & 0.04 & 22.40 & 22.43 & 48.50 & 6.67 \\
4 & 0.04 & 21.70 & 22.26 & 47.96 & 8.08 \\
5 & 0.04 & 21.40 & 22.53 & 47.45 & 8.62 \\
6 & 0.04 & 21.29 & 22.77 & 47.18 & 8.77 \\
7 & 0.04 & 21.25 & 22.90 & 47.06 & 8.79 \\
8 & 0.04 & 21.24 & 22.95 & 47.02 & 8.79 \\
9 & 0.04 & 21.23 & 22.97 & 47.01 & 8.78 \\
10 & 0.04 & 21.23 & 22.98 & 47.01 & 8.78 \\
\hline
\end{tabular}

4.4.5. Variance Decomposition. Variance decomposition can analyze the contribution of structural shocks that affect endogenous variables. Therefore, the variance decomposition results can reflect the contribution of China's economic growth, energy intensity, and industrial development to the structural impact of carbon emissions. From the variance decomposition results of carbon emissions (see Table 11), we can see that carbon emissions of their variance contribution rates remain at around $21.23 \%$ for a long time, and the industrial development of long-term stability of variance contribution ratio of the carbon emissions is $8.78 \%$, which shows that industrial development has less effect on carbon emissions; that is, rapid industrial development does not directly affect the growth of carbon emissions. On the other hand, the contribution rate of China's economic growth to the variance of carbon emissions is relatively large, reaching $27.97 \%$ at the beginning and stabilizing at about $22.98 \%$ thereafter. This indicates that China's economic growth has a great impact on the change of carbon emissions, that is, China's economic growth is one of the main factors affecting carbon emissions. It is important to note that the variance contribution ratio of the energy intensity of carbon emissions was as high as $41.12 \%$ in the beginning, then also experienced a process of rising sharply, and basically remained stable after the variance contribution rate at $47.01 \%$, which means that the impact of energy intensity change of carbon emissions is crucial; this also verifies that the energy intensity in carbon plays a leading role in the conclusion. Therefore, the government should invest more labor or capital to strengthen technological innovation, exploit and utilize clean energy, reduce the dependence of the economy on energy, and enhance the competitiveness of energy-dependent industries, to achieve the goal of reducing carbon emissions more effectively and promote the green and coordinated development of the economy and society.

\section{Conclusions and Policy Recommendations}

5.1. Conclusions. Since the founding of the People's Republic of China, China's economic growth, energy efficiency, and industrial development have experienced several major growth rates and fluctuations, and $\mathrm{CO}_{2}$ emissions have also been greatly affected, possibly resulting in structural changes. Therefore, we used the Bai-Perron break test to answer two questions: Question 1: Does carbon emission show structural changes in the sample period? Question 2: If there are structural changes, at which time points will they appear? According to the test results, we found that there were two structural changes in the carbon emission sequence, the first in 2002 and the second in 2012. The changes in carbon emissions over the years can be divided into three periods: 1970-2001 (a period of slow growth), 2002-2011 (a period of rapid growth), and 2012-2019 (another period of slow growth). Furthermore, the BDS and RESET nonlinear test results show that there is a significant nonlinear relationship between China's carbon emissions and economic growth, energy efficiency, and industrial development. If a conventional linear framework is used for analysis, significant deviations may occur in the test results, leading to biased conclusions about the factors affecting carbon emission. Therefore, we use the model with nonlinear structure to deeply explore the inducing effect of China's economic growth, energy efficiency, and industrial development in carbon emission. Through dynamic mechanism analysis method, we discuss the emission reduction potential of the three factors, respectively, so as to provide a more reasonable basis for precise policies to achieve the carbon reduction target.

First, we use the processed $\mathrm{CO}_{2}$ emissions, China's economic growth, energy efficiency, and industrial development data series to construct a TVP regression model with a nonlinear structure. The results show that the impact of China's economic growth, energy efficiency, and industrial development on carbon emissions has obvious time-varying characteristics, indicating that the construction of a time-varying parameter model is more competitive than the traditional constant coefficient model. Among them, the conduction intensity value of energy use efficiency to $\mathrm{CO}_{2}$ emissions has increased year by year, from 0.45 in 1971 to 0.97 in 2019 . The transmission mechanism of energy use efficiency to carbon emissions is the most significant, and it also shows that changes in energy use efficiency play a leading role in carbon emission reduction. The effect of conduction intensity of China's economic growth on $\mathrm{CO}_{2}$ emissions increases year by year, and the influence coefficient is between 0.65 and 0.96. China's economic growth has a large and stable impact on $\mathrm{CO}_{2}$ emissions, indicating that it plays a major role in long-term $\mathrm{CO}_{2}$ emission reduction. China's economic development has made significant progress, but the high energy consumption economic growth model has also brought a heavy burden on the air environment. The impact of industrial development on $\mathrm{CO}_{2}$ emissions reached a peak of 0.34 in 1977, and the intensity of the impact has basically stabilized at 0.26 . Although the impact of industrial development factors on $\mathrm{CO}_{2}$ emissions is relatively weak, carbon emissions in the industrial sector have long occupied the main part of national carbon emissions. Therefore, Chinese industries need to accelerate the promotion of new models of green transformation, reduce energy consumption and industrial coal consumption, further reduce carbon emissions in the industrial sector, and further promote the sustainable development of China's industry in the future.

Furthermore, in order to measure the time-varying dynamic effects of China's economic growth, energy use 
efficiency, and industrial development on carbon emissions in a global manner, we tried to use the three-dimensional impulse response function to analyze the impact effects. We characterize the short-term, mid-term, and long-term impacts on carbon emissions when the three factors are individually impacted. To find the best nonlinear structural VAR model, we compared the four classes containing the structure of the nonlinear logarithmic marginal likelihood of VAR model, respectively, time-varying parameter vector autoregression with stochastic volatility model (TVP-SV-VAR), time-varying parameter VAR model (TVP-VAR), traditional constant coefficient VAR model (VAR), and regime-switching VAR model $(\mathrm{RS}-\mathrm{VAR}$, regime system state number $=3$ ). According to the Bayesian model comparison criteria, finally, we select logarithmic marginal likelihood biggest TVP-SV-VAR model, at the same time, using Bayes MCMC method to estimate the model parameters. The stereo impulse response results obtained based on the TVP-SV-VAR model show that the shortterm transmission mechanism of energy efficiency on carbon emissions is the most significant, which also indicates that the change of energy efficiency plays a short-term leading role in the carbon emission reduction effect. The impact of China's economic growth has a strong short-term positive effect on carbon emissions, but a weak long-term effect. The overall response intensity of industrial development and economic growth on carbon emissions is similar, but the impact of industrial development on carbon emissions has a shorter duration.

5.2. Recommendations. Comprehensively, the above research conclusion puts forward the following suggestions: First, government departments will accelerate the adjustment and optimization of industrial structure; reduce the economy dependence on energy; invest more labor or capital to strengthen technological innovation; and vigorously develop strategic emerging industries such as energy conservation and environmental protection, new energy, and new materials with exploitation and utilization of clean energy. Second, construction of a resource-saving and environment-friendly society should be considered as an important focus of accelerating the transformation of economic development mode, promoting environmental remediation in depth, driving low-carbon development with air pollution reduction, and promoting the green and coordinated development of the economic and social sectors.

5.3. Research Limitations. We have studied the time-varying effects of China's economic growth, energy efficiency, and industrial development on carbon dioxide emissions and have drawn some valuable conclusions, but there are still some shortcomings, which are mainly reflected in the following aspects:

(1) The factors affecting $\mathrm{CO}_{2}$ emissions are very complex, so many internal details cannot be fully studied. This paper conducts comparative analysis with reference to related research and selects several key indicators for emphatic analysis. Incomplete system research may be different from the actual causes of $\mathrm{CO}_{2}$ emissions. In future research, we will further expand the index system and try to incorporate a more complete index system into the model research.

(2) In the main research methods, there are many methods in this field. We mainly start from the direction of econometrics and extend the general small-scale econometric model to the time-varying econometric model. In future research, we can extend the theoretical model to large and super large models and, at the same time, combine the ideas of other disciplines to explore a composite interdisciplinary method. In future research, we will work harder to explore this field.

\author{
Abrreviations \\ VAR: $\quad$ Vector autoregression \\ RS-VAR: Regime-switching VAR \\ TVP-R: Time-varying parameter regression \\ TVP-VAR: Time-varying parameter VAR \\ TVP-SV - Time-varying parameter vector autoregression \\ VAR: with stochastic volatility \\ EKC: $\quad$ Environmental Kuznets Curve \\ NAFTA: North American Free-Trade Agreement \\ EDGAR: Emissions Database for Global Atmospheric \\ Research \\ UNFCCC: United Nations Framework Convention on \\ Climate Change \\ DOLS: Dynamic Ordinary Least Squared \\ OECD: Organisation for Economic Co-operation and \\ Development \\ MCMC: Markov Chain Monte Carlo.
}

\section{Data Availability}

The $\mathrm{CO}_{2}$ emission data of 6 countries were obtained from the Emissions Database for Global Atmospheric Research (EDGAR) (https://edgar.jrc.ec.europa.eu/). Other data were obtained from the National Bureau of Statistics (https://data. stats.gov.cn/).

\section{Conflicts of Interest}

The authors declare no conflicts of interest.

\section{Authors' Contributions}

Binxia Chen participated in conceptualization and investigation. Donghai Zhou and Binxia Chen contributed to data curation. Yuanying Jiang helped with funding acquisition and supervision. Donghai Zhou and Yuanying Jiang developed the methodology. Donghai Zhou was responsible for visualization and software. Donghai Zhou and Jiahui Li wrote the original draft. Jiahui $\mathrm{Li}$ and Yuanying Jiang reviewed and edited the paper. 


\section{Acknowledgments}

This work was supported by the National Natural Science Foundation of China (No. 71963008); the Joint Cultivation Project of Guangxi Natural Science Foundation (No. 2018GXNSFAA294131); and the Innovation Project of Guangxi Graduate Education (No. YCSW2020175).

\section{References}

[1] F. Black, "Studies of stock market volatility changes," Proceedings of the American Statistical Association, pp. 177-181, 1976.

[2] G. E. Primiceri, "Time varying structural vector autoregressions and monetary policy," The Review of Economic Studies, vol. 72, no. 3, pp. 821-852, 2005.

[3] J. Nakajima, Time-Varying Parameter VAR Model with Stochastic Volatility: An Overview of Methodology and Empirical Applications, Institute for Monetary and Economic Studies, Bank of Japan, Tokyo, Japan, 2011.

[4] J. C. C. Chan and E. Eisenstat, "Bayesian model comparison for time-varying parameter VARs with stochastic volatility," Journal of Applied Econometrics, vol. 33, no. 4, pp. 509-532, 2018.

[5] G. Grossman and A. B. Krueger, "Environmental impacts of a North American free trade agreement," CEPR Discussion Papers, vol. 8, no. 2, pp. 223-250, 1992.

[6] T. Panayotou, "Empirical tests and policy analysis of environment al degradation at different stages of economic development," Working Paper WP238, 1993.

[7] D. Holtz-Eakin and T. M. Selden, "Stoking the fires? $\mathrm{CO}_{2}$ emissions and economic growth," Journal of Public Economics, vol. 57, no. 1, pp. 85-101, 1995.

[8] M. Galeotti, A. Lanza, and F. Pauli, "Reassessing the environmental Kuznets curve for $\mathrm{CO}_{2}$ emissions: a robustness exercise," Ecological Economics, vol. 57, no. 1, pp. 152-163, 2006.

[9] Y. Zheng, S. Chen, S. Chen, and N. Wang, "Does financial agglomeration enhance regional green economy development? evidence from China," Green Finance, vol. 2, no. 2, pp. 173-196, 2020.

[10] Z. Y. Wang and L. M. Wang, "Analysis of the impact of China's economic development on carbon emissions," Journal of Safety and Environment, vol. 6, no. 5, pp. 88-91, 2006.

[11] T. T. Du, F. Mao, and R. Luo, "Analysis of China's economic development and evolution of $\mathrm{CO}_{2}$ emissions," China Population Resources and Environment, vol. 17, no. 2, pp. 94-99, 2007.

[12] D. Guan, K. Hubacek, C. L. Weber, G. P. Peters, and D. M. Reiner, "The drivers of Chinese $\mathrm{CO}_{2}$ emissions from 1980 to 2030," Global Environmental Change, vol. 18, no. 4, pp. 626-634, 2008.

[13] X. Z. Feng and J. Zou, "Economic analysis of $\mathrm{CO}_{2}$ emission trends in China," China Population Resources and Environment, vol. 18, no. 3, pp. 43-47, 2008.

[14] Y. Yang, D. Tang, and P. Zhang, "Double effects of environmental regulation on carbon emissions in China: empirical research based on spatial econometric model," Discrete Dynamics in Nature and Society, vol. 2020, Article ID 1284946, 2020.

[15] X. Li, Y. Song, Z. Yao et al., "Forecasting China's $\mathrm{CO}_{2}$ emissions for energy consumption based on cointegration approach," Discrete Dynamics in Nature and Society, vol. 2018, Article ID 4235076, 2018.
[16] Z. X. Guo, "Decomposition of carbon emission factors in China: LMDI-based decomposition technique," China Population Resources and Environment, vol. 20, no. 12, pp. 4-9, 2010.

[17] R. A. Begum, A. Raihan, and M. N. M. Said, "Dynamic impacts of economic growth and forested area on carbon dioxide emissions in Malaysia," Sustainability, vol. 12, no. 22, p. $9375,2020$.

[18] S. Xu, Y. Zhang, and X. Chen, "Forecasting carbon emissions with dynamic model averaging approach: time-varying evidence from China," Discrete Dynamics in Nature and Society, vol. 2020, Article ID 8827440, 2020.

[19] X. Zou, "VECM model analysis of carbon emissions, GDP, and international crude oil prices," Discrete Dynamics in Nature and Society, vol. 2018, Article ID 5350308, 2018.

[20] P. Sheng, J. Li, M. Zhai, and S. Huang, "Coupling of economic growth and reduction in carbon emissions at the efficiency level: evidence from China," Energy, vol. 213, Article ID 118747, 2020.

[21] K. Dong, R. Sun, G. Hochman, and H. Li, "Energy intensity and energy conservation potential in China: a regional comparison perspective," Energy, vol. 155, pp. 782-795, 2018.

[22] Y. Krozer, "Financing of the global shift to renewable energy and energy efficiency," Green Finance, vol. 1, no. 3, pp. 264-278, 2019.

[23] X. Li, "Study on the impact of energy rebound effect on carbon emission reduction at different stages of urbanization in China," Ecological Indicators, vol. 120, p. 106983, 2021.

[24] N. Yabe, "An analysis of $\mathrm{CO}_{2}$ emissions of Japanese industries during the period between 1985 and 1995," Energy Policy, vol. 32, no. 5, pp. 595-610, 2004.

[25] D. Y. Song and Z. B. Lu, "The decomposition of carbon emission influencing factors and their cyclical fluctuations in China," China Population Resources and Environment, vol. 19, no. 3, pp. 18-24, 2009.

[26] M. Zhang, H. Mu, Y. Ning, and Y. Song, "Decomposition of energy-related $\mathrm{CO}_{2}$ emission over 1991-2006 in China," Ecological Economics, vol. 68, no. 7, pp. 2122-2128, 2009.

[27] Y. G. Zhang, "Impact of changes in economic development patterns on China's carbon emission intensity," Economic Research, vol. 45, no. 4, pp. 120-133, 2010.

[28] Z. Jiang and B. Lin, "China's energy demand and its characteristics in the industrialization and urbanization process," Energy Policy, vol. 49, pp. 608-615, 2012.

[29] X. Zheng, R. Wang, and Q. Du, "How does industrial restructuring influence carbon emissions: city-level evidence from China," Journal of Environmental Management, vol. 276, Article ID 111093, 2020.

[30] L. A. Greening, W. B. Davis, and L. Schipper, "Decomposition of aggregate carbon intensity for the manufacturing sector: comparison of declining trends from 10 OECD countries for the period 1971-1991," Energy Economics, vol. 20, no. 1, pp. 43-65, 1998.

[31] B. Ang, F. Zhang, and K. Choi, "Factorizing changes in energy and environmental indicators through decomposition," Energy, vol. 23, no. 6, pp. 489-495, 1998.

[32] L.-C. Liu, Y. Fan, G. Wu, and Y.-M. Wei, "Using LMDI method to analyze the change of China's industrial $\mathrm{CO}_{2}$ emissions from final fuel use: an empirical analysis," Energy Policy, vol. 35, no. 11, pp. 5892-5900, 2007.

[33] C. A. Sims, "Macroeconomics and reality," Econometrica, vol. 48 , no. 1 , pp. $1-48,1980$.

[34] J. C. Chan and I. Jeliazkov, "Efficient simulation and integrated likelihood estimation in state space models," 
International Journal of Mathematical Modelling and Numerical Optimisation, vol. 1, no. 1-2, pp. 101-120, 2009.

[35] N. M. Del and G. E. Primiceri, "Time varying structural vector autoregressions and monetary policy: a corrigendum," The Review of Economic Studies, vol. 82, no. 4, pp. 1342-1345, 2015.

[36] J. D. Hamilton, "A new approach to the economic analysis of nonstationary time series and the business cycle," Econometrica, vol. 57, no. 2, pp. 357-384, 1989.

[37] C. A. Sims and T. Zha, "Were there regime switches in U.S. monetary policy?" American Economic Review, vol. 96, no. 1, pp. 54-81, 2006.

[38] P. F. Ni, Y. G. Yan, and A. Q. Zhang, "The enigma of underurbanization: an explanation based on international trade," Social Sciences in China, vol. 36, no. 2, pp. 168-185, 2015. 